\title{
Broken rotor bar detection of induction machine using wavelet packet coefficient- related features
}

\begin{abstract}
Fault diagnosis of induction machine can be achieved through wavelet packet analysis to acquire information about its stability and mutability. This paper presents an experimental evaluation of applying wavelet packet transform based on the sideband components, $(1 \pm$ $2 \mathrm{ks}) \mathrm{fs}$, for broken rotor fault detection in induction machines. The wavelet-based method decomposes stator current signal into effective wavelet coefficients. It is shown that the root mean square (RMS) value of wavelet packet coefficients in special frequency bands collectively establishes a feature index. Once the broken rotor bar occurs, this index value increases to distinguish healthy and faulty mode of induction motor as well as fault severity. Additionally, we investigate the left sideband around the fundamental frequency $(50 \mathrm{~Hz}),(1-$ $2 \mathrm{~s}) \mathrm{fs}$, which specifically represents the stator current spectrum of the machine when a rotor bar breakage takes place. An induction motor with one and two bar breakage at 35\%, 50\% and $80 \%$ of full load are investigated. The experimental tests indicate good reliability of different frequency resolution for same frequency component.
\end{abstract}

Keyword: Induction motor; Motor current signature analysis; Broken rotor bar; Wavelet packet decomposition; Root-mean squared 